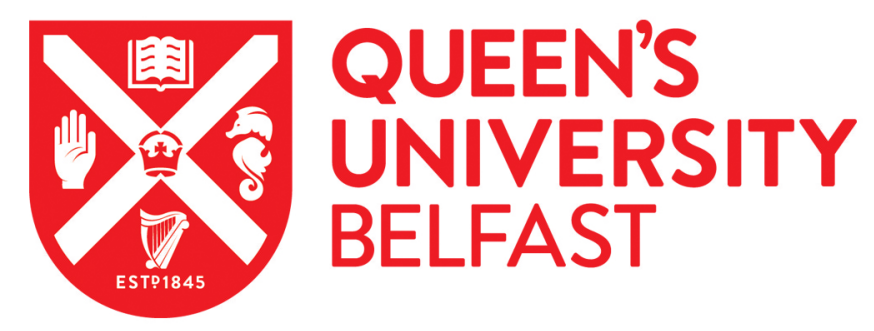

\title{
Economic analysis of ultrasound-assisted oxidative desulfurization
}

Anderson, K., Atkins, M. P., Borges, P., Chan, Z. P., Rafeen, M. S., Sebran, N. H., van der Pool, E., \& Vleeming, J. H. (2017). Economic analysis of ultrasound-assisted oxidative desulfurization. Energy Sources, $12(4), 305-$ 311. https://doi.org/10.1080/15567249.2014.917131

\section{Published in: \\ Energy Sources}

\section{Document Version:}

Peer reviewed version

Queen's University Belfast - Research Portal:

Link to publication record in Queen's University Belfast Research Portal

\section{Publisher rights}

(c) 2017 Taylor \& Francis Group, LLC.

This work is made available online in accordance with the publisher's policies. Please refer to any applicable terms of use of the publisher.

\section{General rights}

Copyright for the publications made accessible via the Queen's University Belfast Research Portal is retained by the author(s) and / or other copyright owners and it is a condition of accessing these publications that users recognise and abide by the legal requirements associated with these rights.

Take down policy

The Research Portal is Queen's institutional repository that provides access to Queen's research output. Every effort has been made to ensure that content in the Research Portal does not infringe any person's rights, or applicable UK laws. If you discover content in the Research Portal that you believe breaches copyright or violates any law, please contact openaccess@qub.ac.uk. 
Full Title: Economic Analysis of Ultrasound-assisted Oxidative Desulfurisation

Shortened Title: Ultrasound-assisted Oxidative Desulfurisation

List of Authors: K. Anderson*a, M.P. Atkins ${ }^{\mathrm{a}}$, P. Borges ${ }^{\mathrm{b}}$, Chan Z.P. ${ }^{\mathrm{a}}$, M.S. Rafeen ${ }^{\mathrm{a}}$, N.H.

Sebran $^{\mathrm{a}}$, E. van der Pool ${ }^{\mathrm{b}}$, J.H. Vleeming ${ }^{\mathrm{b}}$

* Corresponding author tel: +60 123900442, fax: +60 389281474, email:

kris_anderson@petronas.com.my

${ }^{a}$ PETRONAS research, Kawasan Institusi Bangi, Selangor, Malaysia

${ }^{\mathrm{b}}$ Process Design Center B.V., Catharinastraat 21f, Breda, The Netherlands

Key Words: Desulfurisation, Modelling, Oxidation, Peroxide, Sulfur, Ultrasound.

\begin{abstract}
Oxidative desulfurisation is a method of removing sulfur from diesel fuel that has the potential to compete with conventional hydrodesulfurisation processes in refineries. Ultrasound has been shown to greatly increase peroxide oxidation rates of sulfur compounds and can thereby enhance the technology. Through the use of conceptual design modelling, this article critically assesses a range of novel process options. Calculations show that the rate enhancement achieved by ultrasound can translate into reduced process complexity and costs. By modelling various process options, the separation stage of the process is optimised to reveal that a solid adsorbent combined with a combustion regeneration method is the most economically viable. Although the process is limited to feeds with low sulfur content, it is competitive with conventional hydrotreater technology and superior to upgrading an ageing facility.
\end{abstract}




\section{Introduction}

Combustion of sulfur compounds produces oxidised sulfur species such as $\mathrm{SO}_{2}$ that can react with moisture in the air to form acid rain (Clarke and Radojevic, 1987). Documented evidence about the damage this can do to the environment has led to the introduction of legislation around the world that limits the quantity of sulfur permissible in fuels such as diesel (Blakemore et al., 1999). Hydrodesulfurisation is the dominant method used by refineries for lowering the sulfur content of diesel. The drawbacks of this process include the requirement of high temperature, high pressure, large hydrogen consumption and the unnecessary hydrogenation of non-sulfur containing compounds (Robinson and Dolbear, 2006). Although research over the last 20 years has enabled the creation of new catalyst and reactor designs that are able to achieve sulfur contents of $<10 \mathrm{ppm}$, the process still requires high capital and operational expenditures (Stanislaus et al., 2010). Technology that can potentially improve upon this method is therefore of wide-spread interest to the refining industry.

An alternative method for removing sulfur compounds from diesel is to oxidise them. The sulfur in diesel is naturally present in the form of thioethers that are difficult to separate due to similarities in volatility and polarity. By oxidising the sulfur compounds from thioethers to sulfones (see Figure 1), their polarity can be increased thereby enabling them to be separated by liquid-liquid extraction or adsorption onto the surface of a solid adsorbent. Oxidation is most commonly accomplished using a powerful oxidant such as hydrogen peroxide, although others have reported the successful use of various other oxidants (Karas et al., 2007). Oxidative desulfurisation has many potential advantages over conventional hydrodesulfurisation such as: milder operating conditions, lower catalyst costs, and no consumption of $\mathrm{H}_{2}$. Alkylated dibenzothiophenes are known to resist treatment with 
conventional hydrodesulfurisation methods, yet they are easily treated using oxidative desulfurization (Qian, 2008; Otsuki et al., 2000). This can be explained by the alkyl groups increasing electron density around the sulfur atoms, thereby enhancing their oxidation reactivity. This creates the opportunity for oxidative desulfurization to work in synergy with conventional hydrotreating methods.

Many variations on the oxidative theme have been developed to the extent required for commercial application. An American start-up company called Sulphco attempted to commercialise a hydrogen peroxide based oxidation method that uses sonication to enhance the rate of reaction (Teh et al., 2002). This process was proven at a 2000-3000 bbl/day demonstration scale but was not commercialized (Sulphco, 2005). Several other research groups in both industry and academia have developed processes to various levels of maturity, but most are subtle variations on the hydrogen peroxide/acid catalyst method developed by Unipure (Rappas, 2002) and none have reached the stage of full commercialisation.

The objectives of this study were to assess several variations of oxidative desulfurisation technology to explore their practical and economic potential. The process involved generating preliminary conceptual process designs and estimating their capital and operational expenditure requirements. This information was used to compare these variants with conventional hydrodesulfurisation technology. All the process options under consideration were based upon the use of hydrogen peroxide to oxidise the sulfur compounds, as it is relatively cheap and easily sourced.

\section{Experimental}


Process models were based upon a combination of mass balance calculations and Aspen Plus simulations. For mass balance calculations a simplification was made by representing all of the sulfur compounds in the diesel feed as 4,6-dimethyldibenzothiophene, as it has been shown to be representative of the sulfur compounds present in partially hydrotreated diesel (Sampanthar et al., 2006). Liquid-liquid phase equilibria were calculated using the Nonrandom Two Liquid (NRTL) activity coefficient model. Economic calculations were based upon industry sourced valuations of standard process engineering equipment. Equipment sizing was estimated on the basis of key equipment parameters and the overall operating costs were estimated by accounting for raw materials, power, utilities, maintenance, labour, etc. Large storage tanks for diesel feedstock were assumed to be outside battery limits (OSBL) and reactant storage vessels were designed for a capacity of 7 days. Stainless Steel 316 was selected as the material for construction for all equipment. Further details of general cost estimating methodology can be found elsewhere (Peters et al., 2002). As the primary focus of this article is process modelling, detailed discussion of supporting experimental data is deemed extraneous. In-depth discussion on how to oxidise sulfur compounds in diesel both with and without ultrasound, can be found elsewhere (Collins et al., 1997; Teh et al., 2002). All calculations are based upon a standard oxidation reaction that uses an 11:1 ratio of formic acid: $\mathrm{H}_{2} \mathrm{O}_{2}$ and a $4: 1$ ratio of $\mathrm{H}_{2} \mathrm{O}_{2}: \mathrm{S}$. All chemicals utilised in this study were purposefully selected to be commercially available on an industrial scale from multiple suppliers. Commercial suppliers of ultrasound technology at both laboratory and industrial scale are widely available.

\section{Results and discussion}




\subsection{Oxidation of Thioethers to Sulfones}

A summary of the process options considered in this study is shown in Figure 2. For the oxidation step, the option of acid catalysed oxidation without ultrasound was compared to that of an ultrasound assisted reaction. Research by Mei et al. (2003) has shown that ultrasound treatment can increase the oxidation rate of dibenzothiophene by up to 5 times. Calculations show that this rate enhancement translates into a nearly $50 \%$ reduction in capital costs. This is due to the rate enhancement eliminating the requirement of an oxidation reactor, as the ultrasound probe can be mounted into a pipeline. Figure 3 shows a conceptual process scheme that illustrates how ultrasound probes can be utilised in a continuous process. Additional savings can also be made by eliminating the requirement of a phase transfer agent to enhance mixing, due to the extreme turbulence obtained by ultrasound induced cavitation (Suslick, 1986). The options I-1 and II-1 in Table 1 compare the costs of the process for with and without the use of ultrasound and show that the ultrasound option reduces the operating costs by approximately $30 \%$. This is primarily due to the greater simplicity and smaller equipment size.

\subsection{Separation of Sulfones from Diesel}

Several options for separating sulfones from the diesel feed were considered, as experimental studies showed it to be far more challenging than the oxidation step. In total there were 4 separation methods considered for economic analysis, denoted as 1, 2a, $2 \mathrm{~b}$ and 3 in Table 1. Table 1 also summarises the conclusions of the process modelling of the different options. The utilities costs vary greatly and primarily depend upon the choice of regeneration method selected. Liquid-liquid extraction is the most expensive option primarily due to the high cost of distilling large volumes of extraction solvent. Whilst liquid-liquid extraction involves lower capital investment, its energy utility costs are high due to the large solvent flows 
involved. Co-extraction of diesel into the extract solvent phase will also significantly add to the process cost, as this is difficult to recover.

Research into the adsorption of sulfones using silica by Lim et al. (2012) was reproduced in the author's own laboratory and showed that $1 \mathrm{~g}$ of silica can treat up to $26 \mathrm{~g}$ of diesel before requiring regeneration. Considering that many refineries have production capacities in excess of $30,000 \mathrm{bbl} /$ day, it becomes obvious that this method is only applicable to treating relatively low sulfur content feeds and that the efficient recycle of the adsorbent will be critical for economic viability. The two options considered for regeneration of the silica beds were thermal oxidation (i.e. combustion) of the sulfones and solvent extraction. The process for thermal oxidation involves slowly heating the adsorption bed to $500{ }^{\circ} \mathrm{C}$ with hot oxygendepleted air, with the liberated off-gas from thermal oxidation being sent to a Claus unit. Once oxidation is complete, the beds would be cooled back to atmospheric temperature by flowing ambient temperature air through the column. The time period required for the heating and cooling cycle of a $400 \mathrm{~m}^{3}$ bed was calculated to be $>8$ hours. To accommodate such long regeneration times, a 30,000 bbl/day facility would require 6 adsorption beds of $400 \mathrm{~m}^{3}$ to maintain continuous operation.

The second option considered for regeneration of the adsorbent is a solvent wash followed by either distillation or a second stage adsorption. The author's own laboratory experiments showed that washing of the adsorbent bed is a viable option, with this being confirmed in similar studies elsewhere (Lim et al., 2012). Calculations showed this to be a cheaper option than liquid-liquid extraction, as far less solvent is required, thereby minimising distillation costs. 
Option $2 \mathrm{~b}$ utilises a double adsorption method designed to minimise the energy consumed by distillation. Instead of distilling the wash solvent, it is passed through a second adsorbent bed of activated carbon that can be regenerated with a non-polar solvent (e.g. $n$-butane). The logic behind this method is that it reduces the energy required for distillation by isolating the sulfones in a volatile and low heat capacity solvent. Calculations show that the overall capex is higher than for a single stage adsorption, primarily due to the installation of a second set of adsorption beds. However, substitution of a distillation column with a simpler flash column yields utility savings of approximately $50 \%$.

\subsection{Direct Production Costs and Fixed Costs}

The entry in table 1 termed 'other direct production costs' comprises: operating labour, operating supervision, laboratory charges, maintenance/repairs, and operating supplies. The first 3 items are mainly a function of the size and complexity of the process; while the last 2 are related to the maintenance of the plant and are a function of the capital investment (i.e. equipment acquisitions, construction costs, etc.). As the option without the use of ultrasound requires an oxidation reactor, it has higher capital costs and subsequently higher production costs. As the 4 regeneration options all have similar capital expenditure costs and complexity, they also have similar direct production costs. The term 'fixed cost' accounts for all costs not directly related to the production operation such as: depreciation, property taxes, insurance fees, plant overhead costs, administrative costs, financing payback, etc. These costs also correlate directly with the capital cost, hence option I-1 is the most expensive and option II-3 the cheapest.

\subsection{Comparisons with Conventional Hydrotreater Technology}

Calculations show diesel loss is critical to the process economics, as a moderate loss of $2 \%$ can nearly double the overall process cost in some cases. Although efforts can be made to minimise handling losses, oxidation as a general method removes the entire sulfur molecule, 
whereas hydrodesulfurisation removes only the sulfur atoms. The oxidation method therefore produces a sulfone side product stream that for a $500 \mathrm{ppm}$ sulfur content would be in the range of $0.26 \mathrm{wt} \%$ of the feed. Based upon a diesel price of $130 \mathrm{USD} / \mathrm{bbl}$ this loss would add an additional $0.34 \mathrm{USD} / \mathrm{bbl}$ onto the process cost. This was not considered as a process cost in Table 1 as the valuable hydrocarbon contained in the sulfone molecules may be recovered through disposing in a coker or by blending into bunker fuel. Combustion may also be an option, especially if the heat can be recovered in a useful way. Diesel loss is also a problem for conventional hydrotreaters and can add as much as $2 \mathrm{USD} / \mathrm{bbl}$ to the process cost when treating streams in the range of $10,000 \mathrm{ppm}$ sulfur. For hydrotreaters the loss primarily occurs due to unintended cracking of the diesel into various volatile low molecular weight compounds.

Calculations show that oxidative desulfurisation is unlikely to be competitive with hydrotreater technology for sulfur feeds in the range of several thousand ppm sulfur, due to the large quantities of oxidant required and the large quantities of sulfone that are produced. For example, a 30,000 bbl/day refinery processing a 10,000 ppm sulfur diesel feed, would require 560 tonnes/day of hydrogen peroxide. Assuming a hydrogen peroxide price of $1200 \mathrm{USD} /$ tonne would result in a process cost of $>6 \mathrm{USD} / \mathrm{bbl}$ for the hydrogen peroxide feed alone. If it is assumed that all of the sulfur compounds are oxidised benzothiophene, then the quantity of sulfone produced by the process would be 205 tonnes/day or approximately $5 \mathrm{wt} \%$ of the feed. Whilst this is a gross simplification it serves to illustrate the magnitude of materials involved and demonstrates why oxidative desulfurisation is best suited to treating sulfur feeds in the range of a few hundred ppm at most. As a consequence of these conclusions, comparisons were limited to a scenario where a refinery has a hydrotreater that is already producing $500 \mathrm{ppm}$ sulfur, but is required to produce a $50 \mathrm{ppm}$ 
sulfur output due to new environmental legislation. The options available to a refinery in this situation include:

- Upgrade the existing hydrotreater

- Install a new state-of-the-art hydrotreater

- Install an additional treatment process

The data in Table 1 shows that the best oxidative desulfurisation process (option II-1) is competitive with the upgrading of an existing hydrotreater unit. Despite this, refineries are still likely to opt for upgrading an existing hydrotreater unit, as this is a lower risk option than installing new and unproven technology. For ageing refineries, upgrading the hydrotreater is often not an option due to factors such as safety and design limitations. In such a scenario, the only available options are to install a new hydrotreater or to install an additional treatment process such as oxidative desulfurisation. Table 1 shows that installation of an entirely new hydrotreater is nearly double the cost of the best oxidation process, clearly making oxidative desulfurisation the preferred option. These results are in general agreement with the work of Gatan et al. (2004).

\section{Conclusions}

This study has shown that rate enhancements achieved by the use of ultrasound, can translate into significant economic savings. For the separation stage of the process, adsorption onto silica beds that are subsequently regenerated by thermal oxidation (burning) is the most cost effective option. Comparisons with conventional hydrodesulfurisation technology show that oxidative desulphurisation it is not competitive for treating diesel streams with sulfur contents of greater than a few hundred ppm of sulfur. It is however competitive with the option of upgrading an existing hydrotreater and is superior to the option of installing an entirely new hydrotreating facility in an ageing refinery. 


\section{Acknowledgements}

The authors would like to thank the Petroleum Research Fund of PETRONAS for funding and PETRONAS Penapisan Sendirian Berhad for valuable discussion. 

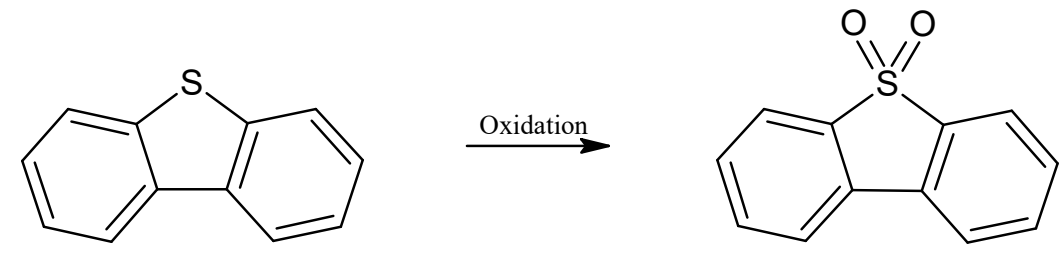

Figure. 1, Oxidation of dibenzothiophene. 


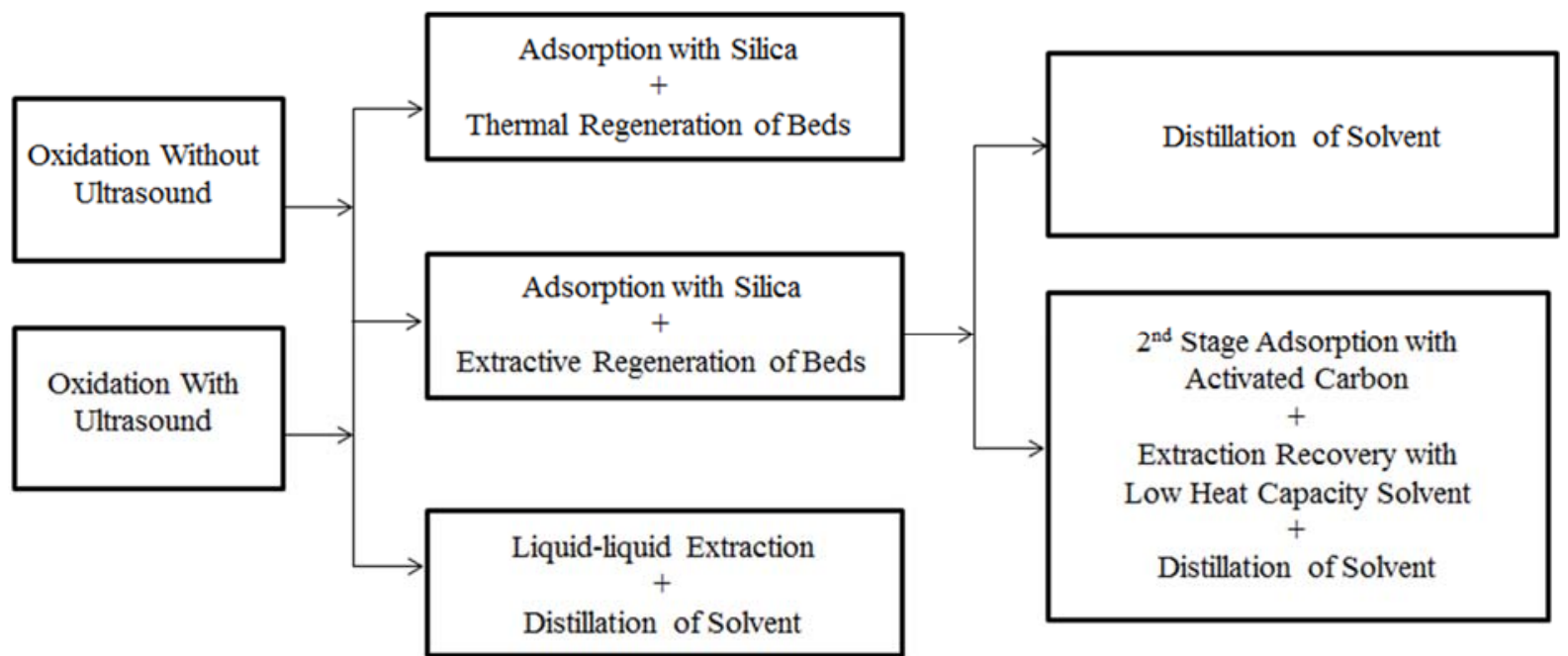

Figure. 2. Overview of the different process scenarios modelled. 


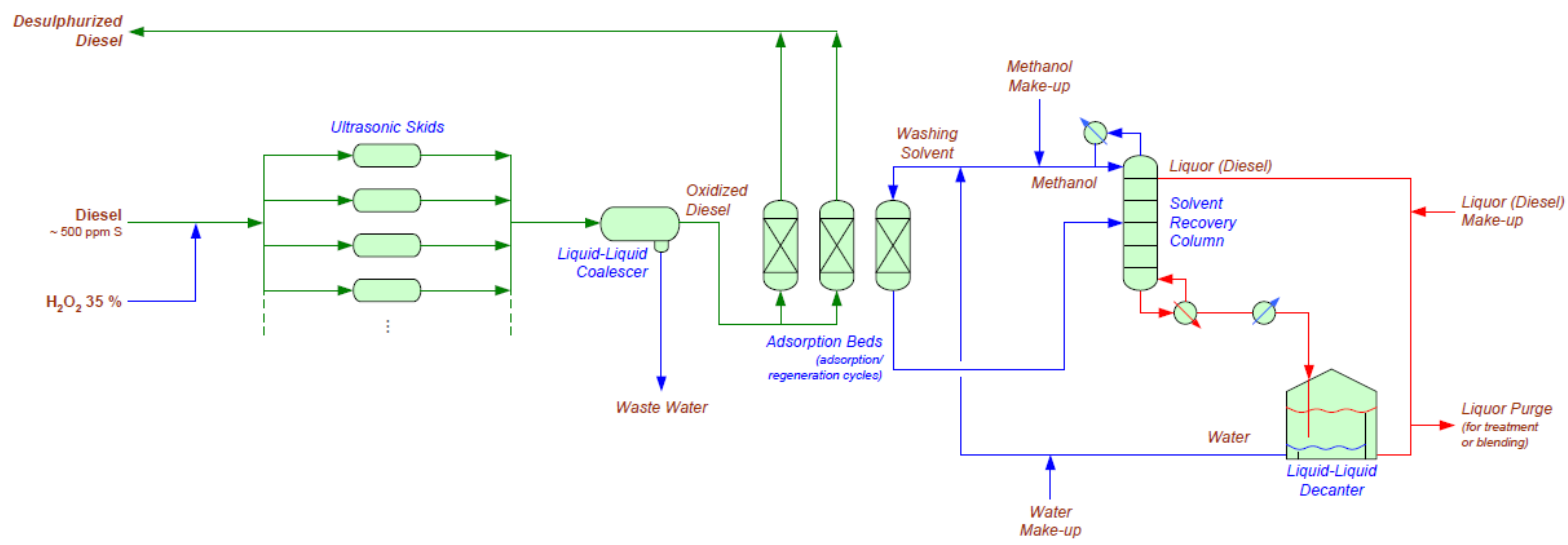

Figure. 3. A conceptual design scheme of process option II-2a. 
Table. 1. Contributions to expenditure for seven process scenarios.

\begin{tabular}{|c|c|c|c|c|c|c|c|c|}
\hline \multirow{2}{*}{\multicolumn{2}{|c|}{ CASE }} & \multicolumn{5}{|c|}{ OXIDATIVE DESULFURISATION } & \multirow{2}{*}{\multicolumn{2}{|c|}{$\begin{array}{c}\text { HYDRO } \\
\text { DESULFURISATION }\end{array}$}} \\
\hline & & \multirow{3}{*}{\begin{tabular}{c|} 
I-1 \\
Without Ultras ound \\
$\begin{array}{c}\text { Adsorption }+ \\
\text { B urning of Beds }\end{array}$ \\
\end{tabular}} & II-1 & II-2a & II-2b & II-3 & & \\
\hline \multirow{2}{*}{\multicolumn{2}{|c|}{\begin{tabular}{|l|} 
Reactor \\
Separation of Sulfones \\
\end{tabular}}} & & \multicolumn{4}{|c|}{ With Ultras ound } & \multirow{2}{*}{$\begin{array}{c}\text { Upgrade } \\
\text { existing } \\
\text { HDS unit * }\end{array}$} & \multirow{2}{*}{$\begin{array}{c}\text { New unit to } \\
\text { process } \\
500 \text { ppms } \\
\text { diesel }\end{array}$} \\
\hline & & & $\begin{array}{c}\text { Adsorption + } \\
\text { B urning of Beds }\end{array}$ & $\begin{array}{c}\text { Adsorption + } \\
\text { Distillation }\end{array}$ & $\begin{array}{c}\text { Double } \\
\text { Adsorption }\end{array}$ & \begin{tabular}{|c|} 
LL extraction + \\
Distillation
\end{tabular} & & \\
\hline \multirow[t]{2}{*}{ Capacity } & BPD & 30,000 & 30,000 & 30,000 & 30,000 & 30,000 & 30,000 & 30,000 \\
\hline & bblyear & $10,000,000$ & $10,000,000$ & $10,000,000$ & $10,000,000$ & $10,000,000$ & $10,000,000$ & $10,000,000$ \\
\hline Capital Cost (2012) & MM\$ & 58.7 & 37.1 & 29.1 & 35.3 & 26.9 & 23.0 & 57.5 \\
\hline \multicolumn{9}{|l|}{ Production cost } \\
\hline Hydrogen Peroxide cost & $\$ /$ bbl & 0.29 & 0.16 & 0.16 & 0.16 & 0.16 & --- & --- \\
\hline Hydrogen cost & $\$ /$ bbl & --- & --- & --- & --- & --- & 0.77 & 0.77 \\
\hline Other auxiliaries & $\$ /$ bbl & 0.04 & 0.02 & 0.03 & 0.04 & 0.01 & - & - \\
\hline Utilities & $\$ /$ bbl & 0.29 & 0.19 & 3.29 & 1.51 & 10.26 & 0.03 & 0.14 \\
\hline Catalyst & $\$ / \mathrm{bbl}$ & 0.02 & 0.03 & 0.03 & 0.03 & 0.03 & 0.14 & 0.19 \\
\hline Other direct production cost & $\$ /$ bbl & 0.38 & 0.28 & 0.24 & 0.27 & 0.23 & 0.23 & 0.57 \\
\hline \begin{tabular}{|l|} 
Fixed cost \\
\end{tabular} & $\$ / \mathrm{bbl}$ & 1.74 & 1.13 & 0.90 & 1.08 & 0.84 & 0.69 & 1.72 \\
\hline \begin{tabular}{|l|} 
TOTAL \\
\end{tabular} & \$/bbl & 2.75 & 1.81 & 4.65 & 3.09 & 11.53 & 1.86 & 3.40 \\
\hline
\end{tabular}

*) A hydrotreater unit producing $500 \mathrm{ppmS}$ diesel from higher sulfur content feedstocks is assumed to already exist on site (operating at a presure of $500 \mathrm{psi}$.

Thydoes presented here correspond to the additional investment and operational costs require to modify and operate the plant to produce a $<50$ ppmS specification. 


\section{References}

Blakemore, F.B., Davies, C., and Isaac J.G. 1999. Effects of changes in the UK energy demand and environmental legislation on atmospheric pollution by sulphur dioxide. Applied Energy 62:283-295.

Clarke, A.G., Radojevic, M. 1987. Oxidation of $\mathrm{SO}_{2}$ in rainwater and its role in acid rain chemistry. Atmospheric Environment 21:1115-1123.

Collins, F.M., Lucy, A.R., and Sharp, C. 1997. Oxidative desulphurisation of oils via hydrogen peroxide and heteropolyanion. Journal of Molecular Catalysis A: Chemical 117:397-403.

Gatan, R., Barger, P., Gembicki, V., Molinari, D., and Cavanna, A. 2004. Oxidative desulfurization: a new technology for ULSD. American Chemical Society, Division of Fuel Chemistry 49: 577-579.

Karas, L.J., Han, Y.Z., and Leyshon, D.W. 2007. Organosulfur oxidation process. US Patent $7270742 \mathrm{~B} 2$.

Lim, S.M., Kim, J.N., Park, J., Han, S.S., Park, J.H., and Jung, T.S. 2012. Energy-Efficient Sulfone Separation Process for the production of ultralow sulfur diesel by two-Step adsorption. Energy Fuels 26:2168-2174.

Mei, H., Mei, B.W., and Yen, T.F. 2003. A new method for obtaining ultra-low sulfur diesel fuel via ultrasound assisted oxidative desulfurization. Fuel 82:405-414.

Otsuki, S., Nonaka, T., Takashima, N., Qian, W., Ishihara, A., Imai, T., and Kabe, T. 2000. Oxidative desulfurization of light gas oil and vacuum gas oil by oxidation and solvent extraction. Energy Fuels 14:1232-1239.

Peters, M., Timmerhaus, K., and West, R. 2002. Plant Design and Economics for Chemical Engineers. 5th Ed. McGraw-Hill Science. 
Rappas, A.S. 2002. Process for removing low amounts of organic sulfur from hydrocarbon fuels. US Patent 6402940B1.

Robinson, P.R., and Dolbear, G.E. 2006. Practical Advances in Petroleum Processing :177218.

Sampanthar, J.T., Huang, X., Jian, D., Teo, Y.N., Xu, R., and Wong, P.K. 2006. A novel oxidative desulfurization process to remove refractory sulfur compounds from diesel fuel. Applied Catalysis B: Environmental 63:85-93.

Stanislaus, A., Marafi, A., and Rana, M.S. 2010. Recent advances in the science and technology of ultra low sulfur diesel (ULSD) production. Catalysis Today 153:1-68. Sulphco Quarterly Business Report November 2005, Securities and Exchange Commission Accession Number 0001019687-05-003103.

Suslick, K.S. 1986. Ultrasound in Synthesis, Modern Synthetic Methods 4:1-60.

Teh, F.Y., Mei, H., and Hung-Mou, S.L. 2002. Oxidative Desulfurization of Fossil Fuels with Ultrasound. US Patent 6402939B1.

Qian, E.W. 2008. Development of novel nonhydrogenation desulfurization process -oxidative desulfurization of distillate. Journal of the Japanese Petroleum Institute 51:1431. 